\title{
A captura e produção da sexualidade em tempos de flexibilização do capital neoliberal ${ }^{1}$
}

\author{
Janaina de Souza Monteiro ${ }^{2}$ \\ Leonardo Lima Ribeiro
}

\begin{abstract}
Resumo: Partindo de premissas de Michel Foucault, conquanto nelas não se fixando, o presente trabalho explicita a sexualidade enquanto um instrumento biopolítico na atual configuração do modo de produção capitalista. É, ao mesmo tempo, mobilizado pela hipótese de que o capital neoliberal redimensiona de maneira significativa distintos campos da existência humana, tornando-os flexíveis, embora por vezes acoplados a determinados anacronismos. Neste contexto, a sexualidade é também redimensionada, anunciada ao fim do texto como expressão individual polimórfica, subsumida aos imperativos vigentes da economia política neoliberal.
\end{abstract}

Palavras-chave: Capital. Neoliberalismo. Sexualidade. Biopolítica. Biopoder.

Abstract: Starting from Michel Foucault's premises, although not sticking with them, this paper explicits sexuality as a bio-political mechanism in the current configuration of the capitalist mode of production. And, at the same time, it is mobilized by the hypothesis that neoliberal capital resizes significantly different fields of human existence, making them flexible, although sometimes coupled with certain anachronisms. In this context, sexuality is also resized, being announced in the end of the text as a polymorphic individual expression, subsumed to current imperatives of neoliberal political economy.

Keywords: Capital. Neoliberalism. Sexuality. Biopolitics. Biopower.

Resumen: Partiendo de premisas de Michel Foucault, este artículo explica la sexualidad como un mecanismo biopolítico en la configuración actual del modo de

\footnotetext{
${ }^{1}$ Recebido em 11/09/2015 e aprovado em 12/06/2016.

${ }^{2}$ Mestranda em Filosofia pela Universidade Federal do Ceará (UFC) e bolsista CAPES. Contato: janainamonteiro.jsm88@gmail.com.

${ }^{3}$ Mestre em Filosofia pela Universidade Estadual do Ceará (UECE). Contato: leoribeiro22@gmail.com.
} 
$|176|$

A captura e produção da sexualidade...

producción capitalista. El artículo es, al mismo tiempo, movilizado por la hipótesis que el capitalismo neoliberal cambia significativamente el tamaño de diferentes ámbitos de la existencia humana, haciéndolos flexibles, aunque a veces acoplado a anacronismos determinados. En este contexto, la sexualidad también se cambia, ella es anunciada en el fin del texto como expresión individual polimorfa, subsumida a los imperativos actuales de la economía política neoliberal.

Palabras clave: Capital. Neoliberalismo. Sexualidad. Biopolítica. Biopoder.

\section{Introdução}

O presente trabalho tem como objetivo compreender o papel da sexualidade enquanto instrumento biopolítico dentro da atual configuração do modo de produção capitalista. Para tanto, pensa-se ser necessário a operação de uma análise inicial de alguns conceitos abordados pelo filósofo francês Michel Foucault (1926-1984), os quais, ao que parece, são muito importantes para a compreensão da temática em questão. Neste sentido, utilizaremos num primeiro momento como referencial teórico a seguinte bibliografia do autor: História da sexualidade I: a vontade de saber (1976), Em defesa da sociedade (1997) e Nascimento da biopolítica (2004) - serão utilizadas ainda obras de alguns comentadores de modo a auxiliar na compreensão dos conceitos problematizados. Contudo, nossa discussão não se esgotará nisso, pois extrairemos conclusões que, apesar de partirem dos argumentos do filósofo, não os envolvem diretamente.

A sexualidade, da maneira como é analisada por Michel Foucault em seu livro História da sexualidade I: a vontade de saber, funciona, dentro de um dispositivo de poder (o dispositivo de sexualidade), como um instrumento privilegiado por meio do qual determinadas práticas de saber/poder têm acesso ao corpo dos indivíduos, a partir de determinado momento histórico. Tais práticas, ressalte-se, participam de um novo modo de atuação do poder estatal, o qual toma como objeto a vida do homem enquanto ser vivo. $\mathrm{O}$ advento desse novo tipo de poder coincide, justamente, com a configuração de uma nova forma de organização da 
sociedade e de um novo modo de produção correspondente a ela: a sociedade burguesa e o modo de produção capitalista.

Partindo do contexto acima expresso, mas nele não se fixando, nossa hipótese é a de que o capitalismo, enquanto dispositivo produtor de subjetividades e seu desenvolvimento neoliberal e sua racionalidade nos marcos dos Estados contemporâneos que lhe dão aporte, redimensiona de maneira significativa campos essenciais da atividade humana - trabalho, desejo e linguagem -, tornando-os flexíveis. Trata-se da produção de uma demanda de individualização diversa, marcada pela exigência da eficiência e da eficácia como requisitos essenciais para a vida dos homens. É nesse contexto mais amplo que é subsumida a prescrição fundamental de um dever: o de um mais gozar das identidades descentradas. Portanto, é nas margens dessa subsunção que a sexualidade tem, decerto, seus delineamentos táticos redimensionados, podendo ser aqui entendida tanto como uma das articulações dispostas entre os níveis micro e macropolíticos (instrumento privilegiado de produção de subjetividades) quanto, por conseguinte, como expressão do individualismo polimórfico e multifacetado o qual torna-se não só palavra de ordem, mas a expressão desejante dos imperativos hodiernos da economia política neoliberal.

Para melhor desenvolver o que é proposto acima, disporemos a exposição em três momentos. No primeiro deles, abordaremos os conceitos de poder disciplinar, biopolítica e biopoder, de modo a situar conceitualmente a discussão nos termos de Foucault; no segundo, ainda fazendo apelo a este autor, trataremos do conceito de capitalismo enquanto dispositivo de poder e seu novo modo de configuração em articulação com os Estados que lhe dão suporte (biopoder); por fim, num terceiro momento, discutiremos como a sexualidade pode ser compreendida filosoficamente nos dias atuais, tomando em alta conta a configuração contemporânea específica das sociedades capitalistas, mescladas aos dispositivos disciplinares ainda cronicamente reconfigurados no modo de racionalidade neoliberal. Apresentaremos ainda, a título de conclusão, como alguns pensadores atualmente abordam a questão da sexualidade neste contexto. 
| 178 |

A captura e produção da sexualidade...

\section{Poder disciplinar, biopolítica e biopoder}

Na aula do dia 17 de março de 1976 de seu curso no Collège de France, Michel Foucault diz que houve, no século XIX, a emergência de um dos fenômenos fundamentais no que concerne ao modo de atuação do poder estatal. Tal fenômeno se caracteriza pelo que ele chama de "assunção da vida pelo poder", isto é, começa a se delinear nesse período uma preocupação com o "homem enquanto ser vivo [...] que conduz ao que se poderia chamar de estatização do biológico" (FOUCAULT, 1997, p. 286). Segundo sua exposição, essa preocupação passa a ter espaço, relativamente à política estatal, graças a transformações ocorridas no modo de compreensão do que é a vida para uma certa teoria do direito, a teoria clássica da soberania.

Nessa teoria, o direito de vida e de morte é um dos atributos fundamentais do soberano, isto é, ao soberano cabe o direito de "fazer morrer e deixar viver" segundo sua vontade. Foucault explica que esse direito que se exerce sobre a vida é em realidade o direito que o soberano tem de matar. A vida, assim, é considerada como um direito somente enquanto algo de que o soberano pode dispor. Nesse sentido, o autor relata que houve uma transformação gradual no direito político que acabou, não por substituir, mas por modificar a antiga formula do direito soberano de fazer morrer e deixar viver, invertendo-a: surge assim um novo direito, ou melhor, um poder de "fazer viver e deixar morrer". É a partir dessa inversão que a vida começa a aparecer como um problema político.

Analisando o surgimento vida como problema a ser pensado pelo campo político a partir do nível dos mecanismos, das táticas, das tecnologias de poder, o filósofo aponta que se vê aparecer, mais ou menos desde a metade do século XVIII, uma nova tecnologia do poder a qual subsumi a tecnologia de poder disciplinar, que, como sabemos, lhe é anterior historicamente (mas não estruturalmente na contemporaneidade). Cabe salientar que a tecnologia de poder disciplinar, forjada em seus aspectos fundamentais entre o século XVII e o início do século XVIII, funciona como uma anátomo-política cujas práticas incidem diretamente sobre os corpos individuais 
dos homens, tendo por objetivo principal distribuir e ordenar esses corpos no espaço, trabalhando-os, treinando-os de forma a maximizar e otimizar sua força para, em seguida, extraí-la sob a forma de trabalho útil. Pode-se afirmar que esta é uma tecnologia disciplinar do trabalho.

Pois bem, a nova tecnologia de poder que surge posteriormente às múltiplas tecnologias disciplinares, incorpora o objetivo de maximização e extração das forças corporais talhado pela disciplina, contudo seu alvo não é o corpo individual do homem, o homem-corpo. Essa tecnologia de poder se dirige à vida do homem enquanto ser vivo, o homem-espécie. Foucault chama esta tecnologia de biopolítica. Segundo o autor, a biopolítica é "uma tecnologia de poder que não exclui a técnica disciplinar, mas que a embute, que a integra, que a modifica parcialmente e que, sobretudo, vai utilizá-la implantando-se de certo modo nela, e incrustando-se efetivamente graças a essa técnica disciplinar prévia" (FOUCAULT, 1997, p. 288-9). Portanto, por não estar no mesmo nível de atuação da disciplina, por este motivo não necessita excluí-la.

Como dito, os níveis em que atuam estas duas tecnologias de poder são distintos. Enquanto a disciplina atua sobre os corpos de forma a individualizá-los, a biopolítica toma esses corpos em conjunto, uma massa global que é afetada por processos (natalidade, mortalidade, doenças etc.) que são inerentes à vida. É justamente sobre estes processos que a biopolítica irá agir buscando compreender seu funcionamento e ocorrência, não para os suprimir, mas para controlá-los, regulá-los e, eventualmente, modificá-los conforme seja o caso. Enquanto as disciplinas funcionam buscando maximizar a força do corpo individual, a biopolítica busca assegurar sobre a população uma regulamentação. Assim, a disciplina, por seu lado, desenvolve-se no domínio topológico das instituições, zonas múltiplas em tenso equilíbrio as quais são passíveis de crônicos rearranjos (afinados à "ordem científica dos discursos" tecnológicos da vez); a biopolítica, por outro lado, instala-se a partir das operações de uma unidade, a saber: a do Estado. Ora, é o fato mesmo de esses conjuntos de 
$\mid 180$ |

A captura e produção da sexualidade...

mecanismos de poder ("tecnologias de dominação") estarem em níveis distintos - operando em registros singulares (multiplicidade institucional/unidade estatal), conquanto interconectáveis e passíveis de fricções interpenetráveis - que permite a eles não se excluírem e poderem articular suas práticas.

É precisamente a atuação articulada desses dois conjuntos de mecanismos de poder que irá caracterizar aquilo que Foucault chama de biopoder (FOUCAULT, 1976, p. 131). O biopoder é esse poder que tem como alvo a vida dos homens em conjunto, e que se exerce através da articulação entre o controle e o aperfeiçoamento dos corpos individuais e a gestão e regulamentação dos processos vitais das populações. Devemos identificar que o advento desse novo tipo de poder coincide, justamente, com o declínio do antigo regime da soberania e a configuração de uma nova forma de organização da sociedade e de um novo modo de produção correspondente a ela: a sociedade burguesa e o modo de produção capitalista.

O biopoder é indispensável ao desenvolvimento do capitalismo(FOUCAULT, 1976, p. 132-3), pois permite a composição de uma força de trabalho adequada às suas necessidades. Ou melhor, a elaboração de um corpo dinâmico de trabalhadores que passe a estar compreendido nos marcos de um aparelho capitalista de produção. Os trabalhadores, desse modo, tornam-se mais produtivos justamente porquê de antemão são interpelados para a docilidade. Portanto, como meio de garantir a eficácia da gestão do corpo majoritário desses trabalhadores segue-se o desenvolvimento de aparelhos estatais destinados à constituição e majoração artificiosa de formas de vida como campos de expressão na forma de labor ou tempo de trabalho socialmente necessário (homens contratualmente determinados à subsunção de suas existências enquanto força de trabalho). ${ }^{4}$

${ }^{4}$ Cf. Foucault (2008). Ver especialmente a terceira parte intitulada "Disciplina" em que o autor trabalha a importância das disciplinas para o adestramento dos copos visando sua docilização e a extração de suas forças de forma útil, necessárias não somente para as instituições disciplinares, mas inclusive para as fábricas. 
O corpo identificado como força de produção, força de trabalho se torna alvo de interesse do capitalismo liberal. $\mathrm{E}$ os mecanismos inerentes ao biopoder lhe servem de apoio e combustível, porquanto proporcionem instrumentos para a produção e reprodução desta força de trabalho, auxiliem na organização social das populações e, mais importante, garantam a reprodução das relações de dominação e exploração (Idem). A preocupação com a população no contexto histórico de amadurecimento do capitalismo ${ }^{5}$ surge, para além da necessidade econômica do sistema de produção, como uma preocupação política de cunho governamental no cerne dos Estados que garantem a manutenção deste sistema.

${ }^{5} \mathrm{O}$ que não significa que devamos identificar o surgimento do capitalismo com o período em questão (entre meados do século XVII e decorrer do século XIX). Como bem sabemos as origens do capitalismo remontam ao declínio e fim da idade média. Grupos burgueses, por exemplo, já existiam entre os séculos XII e XIII, tomando aceleração de alguns de seus contornos mais ou menos bem delineados a partir do século $\mathrm{XV}$, com o renascimento. Para aprofundamento dessa questão ver, por exemplo, o que nos diz Fernand Braudel no terceiro capítulo do segundo volume de seu clássico Civilização material, economia e capitalismo - séculos XV-XVIII - Os jogos das trocas (BRAUDEL, 1996, p. 207). Ressalte-se, contudo, que o que importa definir para os objetivos nesta e na próxima seção deste trabalho é fundamentalmente o amadurecimento de um certo aparelho de Estado europeu e suas operações biopolíticas, cada vez mais fortalecidas em paralelo à pressão da economia capitalista em todas as esferas do social - economia que avança inclusive sobre os modos de procedimento dos Estados modernos. Estes, por seu lado, não deixam de ter modos operação próprios. E uma das contribuições de Foucault é realçar justamente isso, ao demarcar a mobilidade dos mecanismos estatais biopolíticos elaborados através de uma economia social burguesa amadurecida. Tratam-se de processos políticos os quais paradoxalmente, rebatendo sobre a própria economia burguesa que lhes deu modulação inicial, intentam produzir unidades vitais de justificação da subjetividade liberal, o que também é reforçado por meio da pluralidade de distintas instituições sociais, que, por seu lado, têm dispositivos imanentes específicos. Por meio da totalidade dessa complexidade são exercidas a diversidade da produção de modos vida como constituição do corpo social humano moderno. 
$\mid 182$ |

A captura e produção da sexualidade...

Este biopoder, sem a menor dúvida, foi elemento indispensável ao desenvolvimento do capitalismo, que só pôde ser garantido à custa da inserção controlada dos corpos no aparelho de produção e por meio de um ajustamento dos fenômenos de população aos processos econômicos. Mas, o capitalismo exigiu mais do que isso; foi-lhe necessário o crescimento tanto de seu reforço quanto de sua utilizabilidade e sua docilidade; foram-lhe necessários métodos de poder capazes de majorar as forças, as aptidões, a vida em geral, sem por isto torná-las mais difíceis de sujeitar se o desenvolvimento dos grandes aparelhos de Estado, como instituições de poder, garantiu a manutenção das relações de produção, os rudimentos de anátomo e de biopolítica, inventados no século XVIII como técnicas de poder presentes em todos os níveis do corpo social e utilizadas por instituições bem diversas (a família, o Exército, a escola, a polícia, a medicina individual ou a administração das coletividades), agiram no nível dos processos econômicos, do seu desenrolar, das forças que estão em ação em tais processos e os sustentam; operaram, também, como fatores de segregação e de hierarquização social, agindo sobre as forças respectivas tanto de uns como de outros, garantindo relações de dominação e efeitos de hegemonia; o ajustamento da acumulação dos homens à do capital, a articulação do crescimento dos grupos humanos à expansão das forças produtivas e a repartição diferencial do lucro, foram, em parte, tornados possíveis pelo exercício do biopoder com suas formas e procedimentos múltiplos. O investimento sobre o corpo vivo, sua valorização e a gestão distributiva de suas forças foram indispensáveis naquele momento (FOUCAULT, 1976, p. 132-3).

Abordaremos, a partir deste ponto, como capitalismo se desenvolve no interior de um tipo de racionalidade política conhecido por liberalismo e, também, como é possível que 
seu funcionamento determine modos de existência e produza subjetividades adequadas à sua lógica.

\section{Do liberalismo político ao neoliberalismo como arte de governar os vivos}

No curso do ano de 1979, intitulado O nascimento da biopolítica (2004), Foucault analisa como surge e funciona a tecnologia de governo na qual pôde se desenvolver a tecnologia biopolítica. Esse tema foi abordado, em princípio, apenas a título de introdução, contudo, acabou tomando a totalidade temática do curso.

Nesse contexto, o autor analisa o surgimento, entre os séculos XVII e XVIII, de uma nova forma de racionalização da prática governamental chamada razão de Estado. Segundo o ele, a razão de Estado se caracteriza por considerar o Estado, em sua especificidade, como uma realidade específica e autônoma, a qual deve respeitar certo número de princípios e regras que lhe excedem e são exteriores. Este conjunto de regras, em princípio, admite que o Estado deve buscar se fortalecer em relação aos outros Estados por meio da acumulação de riquezas, aumentando sua população e criando um ambiente de regulamentação interno à esteira de mecanismos institucionais, militares e diplomáticos que permitam garantir a pluralidade dos Estados e o equilíbrio entre eles, mesmo em uma situação necessária de constante concorrência (cf. FOUCAULT, 2004, p. 9).

Por outro lado, para poder garantir seus objetivos externos, que são [auto]limitados, o Estado deve adotar, no que poderíamos intitular hoje de política interna, um Estado de polícia que implica a regulamentação e o controle das atividades dos indivíduos que o compõem. Aqui, se os objetivos externos do Estado são limitados (relativos a outros Estados, por exemplo), os objetivos internos são ilimitados, isto é, para garantir que o Estado possa manter certo equilíbrio concorrencial com os outros Estados, quem governa terá que regulamentar ilimitadamente a vida de seus súditos em 
| 184 |

A captura e produção da sexualidade...

todas as diferentes camadas (entram aqui em jogo, exatamente, os mecanismos do biopoder estatal).

É nesse contexto que surgem inclusive discussões, no âmbito do direito, acerca da possibilidade de limitação da interferência do Estado na vida dos indivíduos. O direito, que antes era utilizado como multiplicador do poder real, com o desenvolvimento dessa nova racionalidade governamental da razão de Estado, passará a servir à tentativa de limitá-la de fora, no campo jurídico, impedindo o avanço indefinido da ação estatal que até ali já tomava corpo enquanto Estado de polícia. Contudo, essa tentativa de limitação extrínseca à razão de Estado, própria das exigências jurídicas à época, só poderia funcionar até determinado ponto, apenas se objetando a essa racionalidade em questão se, porventura, o governo ultrapassasse os limites da sua legalidade, isto é, quando fosse o caso de ser considerado como ilegítimo.

Por conseguinte, nos diz Foucault, adiante irá surgir uma forma de limitação da ação estatal que será interna a própria razão de Estado. Essa limitação dizia respeito a uma restrição de fato, que se delineava de forma geral em função dos objetivos de governo, tendo por função dividir as coisas a se fazer e, fundamentalmente, não sendo posta nem pelos que governavam nem pelos que eram governados. Tratava-se de uma demarcação geral, racional "entre o que é para fazer e o que não é para fazer". Isso caracterizava o que Foucault chamava de razão governamental crítica.

Ainda para nosso autor, a questão fundamental para esse tipo razão governamental seria a de "como não governar demais", opondo-se ao excesso de governo relativamente às regras de circulação internas à racionalidade de mercado, com seu laissez-faire (deixar-fazer). Com efeito, o instrumento intelectual que permitia a emergência de uma autolimitação da razão governamental era, justamente, a economia política enquanto "reflexão geral sobre a organização, a distribuição e a limitação dos poderes em uma sociedade" (FOUCAULT, 2004, p. 19). Esse novo tipo de racionalidade do governo, fundamentado por uma economia política como autolimitação da "arte de governar" e que tinha por princípio governar o mínimo possível era, decerto, o que 
conhecemos por liberalismo.

Foucault analisa o liberalismo não como teoria, ideologia ou como uma "maneira de a sociedade se apresentar", mas "como princípio e método de racionalização do exercício do governo, [...] que obedece [...] à regra interna da economia máxima" (FOUCAULT, 2004, p. 432). A preocupação nessa nova forma de racionalidade política era a de que os indivíduos enquanto sujeitos de direito (proprietários de si mesmos nas relações de troca) fossem respeitados em sua individualidade e tivessem garantias de liberdade de iniciativa. A sociedade de mercado como eixo de gestão da esfera da produção aparecia então adicionada a uma racionalidade de autocompreensão social como pacto subjetivoobjetivo selado entre cidadãos que circulavam na esfera do mercado como sui juris (senhores de si; donos de sua própria jurisdição), racionalidade vivente que seria simultaneamente administradora de pactos sociais mais amplos (família, por exemplo), tanto quanto condição e fim último da espessura que delimitava os campos de ação do governo Estatal.

É, portanto, a partir do liberalismo como racionalidade moral-jurídico-econômica de mercado e enquanto mediação da inter-relação entre os homens que deve se pôr a questão da necessidade do governo estatal, tanto quanto o problema da espessura delimitadora de suas esferas de ação. Ora, é precisamente aqui que o mercado surge como topologia discursiva a partir da qual a verdade da sociedade será produzida, demarcando simultaneamente o papel do Estado e seus limites em relação ela. De todo modo, para a temática de nosso trabalho, cujas veredas estão atravessadas pela luz da biopolítica contemporânea, o liberalismo como arte de autogoverno a partir produção dos discursos dos homens, suas inter-relações e espaços institucionais ainda é insuficiente. E a razão disso segue adiante.

Para Foucault é preciso que estejamos atentos para o desdobramento e ruptura desse racionalismo liberal como arte de governar os vivos à medida que ele se diferencia em 
$|186|$

A captura e produção da sexualidade...

neoliberalismo, ou seja, uma racionalidade dominante que demarca o lugar das formas biopolíticas de gestão e produção das vidas na contemporaneidade. Justamente nesse sentido, observemos as palavras de Foucault ainda em O nascimento da biopolítica (aula de 21 de março de 1979), quando enuncia que:

A forma geral do mercado se torna um instrumento, uma ferramenta de discriminação no debate com a administração. Em outras palavras, no liberalismo clássico pedia-se ao governo que respeitasse a forma do mercado e se "deixasse fazer". Aqui, transforma-se o laissez-faire em não deixar o governo fazer, em nome de uma lei do mercado que permitirá aferir e avaliar cada uma das suas atividades. O laissez-faire se vira assim no sentido oposto, e o mercado já não é um princípio de autolimitação do governo, é um princípio que é virado contra ele. É uma espécie de tribunal econômico permanente em face do governo. Enquanto o século XIX havia procurado estabelecer, em face e contra a exorbitância da ação governamental, uma espécie de jurisdição administrativa que permitisse aferir a ação do poder público em termos de direito, temos aqui uma espécie de tribunal econômico que pretende aferir a ação do governo em termos estritamente de economia e de mercado (FOUCAULT, 2004, p. 339).

Como é passível de observação, portanto, a reestruturação do mercado e dos modos de produção no seio do capitalismo (levando em consideração também sua financeirização excessiva), mediados agora pela insistência da racionalidade neoliberal como gestão e produção da vida social, passam a avançar com mais radicalidade sobre os modos hierárquico-institucionais de governo das formas de vida (ressalte-se o Estado). Assim, sejamos bastante precisos: trata-se precipuamente de redirecionar e/ou desdobrar, inclusive no tocante ao Estado e instituições claramente não econômicas (isto é, onde o mercado não opera produzindo mercadorias, até mesmo em prisões!), modos de racionalidade imanentes à esfera do mercado (FOUCAULT, 2004, p. 340). Ou melhor, nos lugares em que 
não se opera a produção de mercadorias como engendramento de valores para a circulação no mercado passa-se a, paradoxalmente, diferenciar-se uma grade de inteligibilidade econômica que antes era apenas interna à lógica do mercado e seus sujeitos, tal como a concorrência enquanto intersubjetividade belicosa dos pares. Portanto, a racionalidade de mercado, o que Foucault compreende como neoliberalismo, reduplica-se e objetiva de um modo nefasto penetrar transversalmente os campos inter-relacionais vivos nos quais antes não estava impelida a agir na produção de sujeitos e seus discursos, sujeitos os quais, concorrendo nos múltiplos espaços institucionais enquanto "trincheiras do mundo contemporâneo", passam a agir competitivamente, de toda maneira, como se estivessem a produzir subjetivamente mercadorias, embora nessa concreta ficcionalização não estejam realmente a produzi-las.

No limite, tomando então, precipuamente, o mais-valor mercadológico estritamente do ponto de vista da materialidade subjetiva não producente de mercadorias e seus crivos em diversas organizações, até mesmo o poder público, como nos diz acima Foucault, incita seus membros a racionalmente agir em termos de mercado. Individualmente, então, cada um desses membros em síntese é "um sujeito que, no sentido estrito, procura em qualquer circunstância maximizar seu lucro, otimizar a relação ganho/ perda; no sentido lato: aquele cuja conduta é influenciada pelos ganhos e perdas a ela associados" (FOUCAULT, 2004, p. 353). Trata-se da autovalorização de si como capital sob o registro de uma racionalidade concorrencial disposta num regime de guerra de subjetividades mercadológicas imanentes agora aos espaços (instituições de educação pública, por exemplo) nos quais, paradoxalmente, o mercado estruturalmente não opera na produção de mercadorias enquanto meio de acumulação de riquezas (como era o caso das relações de trabalho explorado, subsumidas às regras dos donos dos meios de produção burgueses -, que também faziam circular as próprias mercadorias, sustentando tanto a espessura funcional do mercado em sua origem capitalista quanto o seu polo complementarmente necessário, a saber, a divisão dos trabalhadores nos âmbitos distintos de 
| 188 |

A captura e produção da sexualidade...

labor). Portanto, não poderia ser de outro modo que, por exemplo, “o tribunal econômico passa a ser o objeto racional de aferição da ação do governo, compreendido agora estritamente em termos de economia e de mercado" (FOUCAULT, 2004, p. 339-41). ${ }^{6}$

\section{A sexualidade nos marcos da racionalidade flexível neoliberal}

Portanto, nessa configuração do capitalismo neoliberal, que tem na racionalidade neoliberal supracitada formas de regulação da pluralidade social, apercebem-se rupturas brutais no tocante aos processos de subjetivação, pelos quais passam então a se colocar no mundo em questão os trabalhadores. Por conseguinte, como desdobramento do que está aqui dito, uma espécie de cultura do empreendedorismo é inaugurada e se instaura como processo de investimento libidinal do trabalhador em si mesmo (o clássico capital humano desenvolvido pela Escola de Chicago) ao passo simultâneo em que se engendra uma dinâmica legal dos afetos de natureza mais polimórfica. Trata-se de uma cultura que tem, como um dos atributos da racionalidade neoliberal acima demarcada, relação direta na produção de sujeitos não apenas nas esferas do trabalho ${ }^{7}$ e do consumo, mas articulação imediata com regimes descentrados de interpelação de sexualidades individuais múltiplas, enquanto formas biopolíticas de vida as quais se autorregulam produtivamente à medida em que procedem como

\footnotetext{
${ }^{6}$ Cf. também: Foucault (2004, p. 306-7).

7 “O problema fundamental, essencial, em todo caso primeiro, que se colocara a partir do momento em que se pretenderá fazer a análise do trabalho em termos econômicos será saber como quem trabalha utiliza os recursos de que dispõe. Ou seja, será necessário, para introduzir o trabalho no campo da análise econômica, situar-se do ponto de vista de quem trabalha; será preciso estudar o trabalho como conduta econômica, como conduta econômica praticada, aplicada, racionalizada, calculada por quem trabalha. O que é trabalhar, para quem trabalha, e a que sistema de opção, a que sistema de racionalidade essa atividade de trabalho obedece?" (FOUCAULT, 2004, p. 307).
} 
espécie de mimese da fluidez produtiva das finanças, do mercado e das formas de produção de individualidade de/em instituições sociais variadas. Tais sexualidades, hoje em dia, estão sendo atualizadas, em seu registro de autoprodução específico, num compasso de expansão de sistemas plurais de gozo (cf. GADELHA, 2009, p. 146-147).

Ao que parece, trata-se de algo que o próprio Foucault não previra inteiramente em História da sexualidade I: a vontade de saber. Nesta obra apresenta sua tese de que a sexualidade não fora integralmente reprimida, conquanto tenha sido interpelada no bojo das sociedades capitalistas à época a se exprimir minuciosamente sob procedimentos discursivos os mais diversos. Entretanto, quando o filósofo atina para polimorfismo de discursos sobre o sexo enquanto taxonomia de expressões sobre a multiplicidade da sexualidade, tinha precisamente o intuito de atestar, à ocasião do contexto por ele analisado (séculos XVII, XVIII, XIX), que tudo que fosse pertencente a esse polimorfismo classificado, direta ou indiretamente, era pelos seus atores relegado dissimuladamente ao "submundo" do social (embora ainda pertencentes a ele), e não projetado para o lado mais evidenciado de sua superfície.

Ora, o que estávamos antes explicitando aqui é algo relativamente diferente do que Foucault apontou na obra supracitada. Pois estávamos a inferir que, atualmente, as taxinomias do discurso sexual, enquanto procedimento racionalizado pelos seus atores como discursos e hábitos dos corpos, estão a passar paradoxalmente a perseverar cada vez mais às claras em nosso mundo atual, não sendo, portanto, produzidas na surdina (na tensão entre legalidade e ilegalidade), no intento de uma dissimulação crônica, mas, contrariamente, [re]elaboradas ad infinitum, para que realmente ocupem a superfície da sociedade agora com determinadas sexualidades polimórficas apercebidas como radicalmente legítimas enquanto formas de vida.

De fato, o que aqui está em questão é um rearranjo paralelo da sexualidade em contínuo reequilíbrio com o mundo do consumo flexível e da lógica dinâmica e empreendedora dos modos de labor, 
| 190 |

A captura e produção da sexualidade...

rearranjo delimitado nos marcos do capitalismo contemporâneo ${ }^{8}$. De todo modo, "[...] o trabalho é experiência igualmente afetiva. Há, portanto, sofrimento no trabalho, porém sofrimento que orienta a inteligência. E se há frustração, o prazer está sempre no horizonte [...] características afetivas [que] estão implicadas na inteligência que arrisca contornar a norma, porém sem alarde, e discretamente quebrar a disciplina" (ARANTES, 2014, p. 129-30).

Sylvio Gadelha, em seu livro Biopolítica, governamentalidade e educação: introdução e conexões, a partir de Michel Foucault (2009), aborda justamente nesse contexto o regime de tipologias individuais que seguem a partir dessa nova configuração do capitalismo, marcando-as com precisão sob a categoria por ele intitulada de indivíduo microempresa. No fundo, fica subentendido, em nosso entendimento, que se trata de categoria anunciada para explicitar a fusão entre formas de vida (campos de discurso em diferentes graus de interação) que devem delimitar a espessura subjetiva dos indivíduos contemporâneos. Tal categoria é fruto de uma cultura do empreendedorismo ${ }^{9}$, propagada pelos intelectuais do neoliberalismo norte-americano, a partir, segundo Foucault, dos estudos empreendidos por Theodore Schultz e Gary Becker, lançando mão da noção de capital humano ${ }^{10}$.

Mas o que vem ser capital humano no entendimento

\footnotetext{
${ }^{8}$ Ver também: Guattari (1990).

${ }^{9}$ Uma excelente revisão teórica sobre como a cultura do empreendedorismo se desenvolve nas periferias do Brasil, por exemplo, plasmadas como zonas "pacificadas" de exceção, sugere-se a leitura atenta do ensaio Depois de junho a paz será total, publicado em O novo tempo do mundo (2014), de Paulo Arantes. Conferir em especial as notas de rodapé $25,26,30,31$ e 32.

10 "Foi o que tentou fazer certo número deles, sendo o primeiro Theodore Schultz, que, no correr dos anos 1950-60, publicou um certo número de artigos cujo inventário se encontra num livro publicado em 1971 chamado Investment in Human Capital. Gary Becker publicou, mais ou menos nos mesmos anos, um livro com o mesmo título, e vocês tem um terceiro texto que é bastante fundamental e mais concreto, mais preciso do que os outros, que é o de Mincer sobre a escola e o salário, publicado em 1975" (FOUCAULT, 2004, p. 304).
} 
desses autores? Capital humano é um conjunto de habilidades, capacidades e destrezas que se tornam valores de troca. Tais atributos empresariais são desvinculados das pessoas, que, conquanto sendo externos a elas, não deixam de lhes pertencer numa determinada imanência constitutiva, expressiva. Agora sendo valores acumuláveis de mercado e se intuindo como tais, as pessoas naturalizam com alegria a crença paralela de que podem almejar postular por autoinvestimento boas posições de trabalho mediante intenso comprometimento orgânico com as instituições da sociedade capitalista contemporânea ${ }^{11}$. O que o próprio Foucault já nos dizia, à espessura das seguintes palavras:

Decomposto do ponto de vista do trabalhador, em termos econômicos, o trabalho comporta um capital, isto é, uma aptidão, uma competência; como eles [Schultz e Becker] dizem: é uma "máquina" [...] A aptidão a trabalhar, a competência, o poder fazer alguma coisa, tudo isso não pode ser separado de quem é competente e pode fazer essa coisa. Em outras palavras, a competência do trabalhador é uma máquina, sim, mas uma máquina que não se pode separar do próprio trabalhador, o que não quer dizer exatamente, como a crítica econômica, ou sociológica, ou psicológica dizia tradicionalmente, que o capitalismo transforma o trabalhador em máquina e, por conseguinte, o aliena. Deve-se considerar que a competência que forma um todo com o trabalhador é, de certo modo, o lado pelo qual o trabalhador é uma máquina, mas uma máquina entendida no sentido positivo, pois é uma máquina que vai produzir fluxos

\footnotetext{
11 “E, com isso, se poderá ver, a partir dessa grade que projeta sobre a atividade de trabalho um princípio de racionalidade estratégica, em que e como as diferenças qualitativas de trabalho podem ter um efeito de tipo econômico. Situar-se, portanto, do ponto de vista do trabalhador e fazer, pela primeira vez, que o trabalhador seja na análise econômica não um objeto, o objeto de uma oferta e de uma procura na forma de força de trabalho, mas um sujeito econômico ativo" (FOUCAULT, 2004, p. 307-8).
} 
|192 |

A captura e produção da sexualidade...

de renda. Fluxos de renda, e não renda, porque a máquina constituída pela competência do trabalhador não é, de certo modo, vendida casualmente no mercado de trabalho por certo salário. [...] e vocês veem que estamos aqui no antípoda de uma concepção da força de trabalho que deveria se vender a preço de mercado a um capital que seria investido numa empresa. Não é uma concepção da força de trabalho, é uma concepção do capital-competência, que recebe, em função de variáveis diversas, certa renda que é um salário, uma renda-salário, de sorte que é o próprio trabalhador que aparece como uma espécie de empresa para si mesmo (FOUCAULT, 2004, p. 308-9).

É justamente no itinerário de sua autoconstituição no bojo desse esquema, que processos subjetivos individuais, por conseguinte, tornam-se eminentemente correlatos, ou melhor, homólogos estruturalmente ao próprio movimento intrínseco do capital. Aqui, o trabalhador não se observa mais como um simples trabalhador, mas como um trabalhador-capital (operário sócio minoritário do patrão), ou seja, como indivíduo, uma vida capital que em si e para si age como microempresa e que auto-investe suas próprias forças internas diferenciais nos diferentes campos institucionais público-privados com os quais se depara e interage.

No neoliberalismo - e ele não esconde, ele proclama isso -, também vai-se encontrar uma teoria do homo oeconomicus, mas o homo oeconomicus, aqui, não é em absoluto um parceiro da troca. O homo oeconomicus é um empresário, e um empresário de si mesmo. Essa coisa é tão verdadeira que, praticamente, o objeto de todas as análises que fazem os neoliberais será substituir, a cada instante, o homo oeconomicus parceiro da troca por um homo oeconomicus empresário de si mesmo, sendo ele próprio seu capital, sendo para si mesmo seu produtor, sendo para si mesmo a fonte de [sua] renda (FOUCAULT, 2004, p. 310-11). 
Assim sendo, "o poder não pode obter um domínio efetivo sobre a vida inteira da população a menos que se torne uma função integrante e vital que cada indivíduo abraça e reativa por sua própria conta e vontade [...] é a própria vida que é visada, no seu processo de produzir e reproduzir-se" (PELBART, 2003, p. 82). Justamente por isso "o imperativo da superação e da construção indefinida de si mesmo, ainda que conciliado pelo infinito de trabalho, no qual empregadores e funcionários se acasalam, engendra uma moral anti-democrática, mesmo que se considere a democracia liberal tradicional ou do bem-estar social" (DUNKER, 2016).

É em meio a esse contexto de auto-investimento do indivíduo microempresa que a produção de discursos de desejo também assume um regime dinâmico, flexível, porquanto não se trata mais de uma conjuntura que tenta pautar os espíritos da época a um único ideal oficial. O indivíduo reproduz, no campo dos desejos enunciados, a lógica flexível do trabalho (multitarefismo funcional ou pluralidade intensiva de atividades) e da circulação de mercadorias, reforçando a produção interna de mais desejo, tal como se estivesse produzindo para si mais riqueza, passando no mesmo compasso de um objeto a outro, tanto quanto tomando como parâmetro a descartabilidade das pessoas como mercadorias fluidas ${ }^{12}$.

12 "Na verdade, perguntar-se sobre as mutações na corporeidade dos sujeitos seria um a forma de determinar o que são aquilo que poderíamos chamar de 'identidades flexíveis', ou seja, identidades que absorvem a dissolução mercantil das determinações de conteúdo (por isso são 'flexíveis'), que flertam com a indeterminação mesmo sendo capazes de conservar a determinação formal de predicação por propriedades (por isso ainda são 'identidades'). Identidades que se expressam em corpos não mais pensados como locus de determinações estáveis de conteúdo. Corpos em mutação e reconfiguração contínua, mas que determinam cada uma de suas figuras sob a forma geral da propriedade, do próprio, da extensão, do domínio consciente da vontade. Nossos corpos perderam qualidade narrativa, eles são habitados pela violência dos fluxos contínuos codificados pelam forma mercadoria, mas eles ainda sabem contar" (SAFATLE, 2015, p. 195). 
|194 |

A captura e produção da sexualidade...

Ao que parece é então nisto que a sexualidade contemporânea está radicalmente implicada: o investimento na própria "riqueza" redimensiona processos subjetivos de mais desejo, que, ao ser aqui anunciado tanto como discurso da livre circulação de afetos quanto como fluxo intensivo de produção de si, passa a ter seus mecanismos procedendo tal qual uma mimese da produção de mais-valia. Surge aqui algo muito curioso: ao espoliar de si todas as forças possíveis o indivíduo microempresa percebe-se ao mesmo tempo acumulando desejos infinitesimais (os quais, ele não o sabe inteiramente, evaporam com grande aceleração); ou seja, ao passo em que se destrói (ressalte-se, inclusive, alguns de seus mecanismos identitários) exprime uma intensa riqueza libidinal e psíquica, que lhe permite, mesmo que esgotado, gozar de imensas alegrias de momento, na crônica sensação de que é vencedor, conquanto plasmado sob o fundo da derrota ${ }^{13}$.

Ora, este não é o funcionário produtivo dos sonhos de qualquer empresa, não é o amante dos sonhos do mundo

13 “Graças à internalização desse ideal o risco de insegurança social produzido pela desregulamentação do trabalho foi suplantado pela promessa de plasticidade absoluta das formas de vida, ou seja, tal desregulamentação se traduziu em liberação da potencialidade de construir projetos conscientes de formas de vida, da mesma maneira que a intensificação do desempenho e das performances exigida pelo ritmoeconômico neoliberal transformou em peculiar modo subjetivo de gozo. [...] A generalização da forma-empresa no interior do corpo social abriu as portas para os indivíduos se autocompreenderem como 'empresários de si mesmos' que definem a racionalidade de suas ações a partir da lógica de investimentos e retorno de 'capitais' e que compreendem seus afetos como objetos de um trabalho sobre si tendo em vista a produção de 'inteligência emocional' e otimização de suas competências afetivas. Ela permitiu ainda a 'racionalização racional do desejo', fundamento normativo para a internalização de um trabalho de vigilância e controle baseado na autoavaliação constante de si a partir de critérios derivados do mundo da administração de empresas. [...] Criando modos de governabilidade muito mais enraizados psiquicamente" (SAFATLE, 2015, p. 199-200). Para mais informações sobre o assunto conferir também Foucault (2004), especialmente as aulas dos dias 14 e 21 de março. Posições dessa natureza também já foram expressas de antemão em Dardot e Laval (2010). 
do consumo, um homem ou uma mulher que, ostentando radicalmente o sucesso em diversos níveis, goza cronicamente com seu próprio desgaste, sua autodestruição vencedora? Essa forma de vida dissoluta não se reduziu hoje a esse monstro grotesco que nos tornamos, monstro com o qual convivemos porque há tempos fomos capturados pelo devir de um sistema reequilibrado de desejo, cuja exigência é simplesmente a de prestar contas com as esferas da produção e do excessivo consumo no capitalismo contemporâneo? Não há um chamamento interpelador voraz (por muitos de nós em [re]produção) que nos clama para uma acelerada existência dinâmica no trabalho, no consumo e na cama, por meio de que, com ou sem estimulantes, impera como dever arrojos autodestrutivos das finitudes humanas, que curiosamente se creem eternas? Essa possibilidade de colocar a própria vida em questão, "uma convulsão interior" de modo a "violar a integridade dos corpos, de profanar as identidades definidas, de destruir a ordem descontínua das individualidades" (MORAES, 2013, p. 311) não é hoje em dia, paradoxalmente sob o pano de fundo de inflamados egocentrismos cristalizáveis, o justo imperativo de um reposicionamento enlouquecido da própria vida, tripartida em trabalho, desejo e linguagem a partir de demandas biopolíticas de transfiguração a todo custo - nos açoitando enquanto para elas sorrimos, embora também retroalimentemos infinitas desesperanças, lá onde o crônico sofrimento nunca está a passar? ${ }^{14}$

Uma consequência disto que abordamos não poderia ser outra que não um contexto de violência extremada, em meio a narcisismos que se debatem inclusive numa sexualidade do mundo atonal, para sentirem que são minimamente felizes. Trata-se de um "coletivo a partir de indivíduos que se dispõem a partilhar

\footnotetext{
14 Para maiores aprofundamentos específicos entre o sofrimento, modos de labor e desejo conferir, por exemplo, Dejours (2015). Cf. também para contextualizações do que aqui está dito no itinerário de um capitalismo à brasileira e, ressalte-se, numa perspectiva psicanalítica mais ampliada de colonização do sofrimento a partir do conceito de condomínio: Dunker (2015). Cf. ainda o trabalho de Viana (2013), e também Kehl (2009).
} 
com outros o egoísmo solipsista de seu estúpido prazer", pois "tanto o isolamento individual como a imersão do indivíduo na massa excluem a intersubjetividade propriamente dita, o encontro com o Outro" (ŽIŽEK, 2014, p. 50). É contra esse cinismo pósideológico escabroso, imanente ao capitalismo atual, que Vladimir Safatle também se volta em Cinismo e falência da crítica (2008).

\section{Algumas ponderações conclusivas}

Contudo, e como conclusão do presente trabalho, algumas considerações plasmadas na forma de ressalvas se fazem necessárias. A primeiras delas pode ser aqui anunciada por meio da ponderação de que (conquanto tratemos acima da biopolítica e da sexualidade por ela envolvida e produzida como forma de vida flexibilizada, imanente ao narcisismo dinâmico subsumido no movimento autoproducente dos sistemas de governabilidade neoliberal, desdobrando-se em paralelo com os modos contemporâneos de trabalho tutelados a partir de técnicas inovadoras e eficazes próprias de uma racionalidade dominante neoliberal) a sistemática biopolítica, aqui em jogo para demarcação das formas de vida anunciadas à esteira da linguagem, do trabalho, do mercado e do desejo, não é vertida de um modo inteiramente pacífico.

É preciso, para tanto, enfatizar que o desdobramento das operações sistemáticas da racionalidade dominante neoliberal enquanto forma de governo producente de sujeitos têm processos de domínio específicos nos campos em que se diferencia (trabalho, desejo, linguagem etc.). Isto é, deve-se pressupor que há, de antemão, uma espécie de desequilíbrio crônico entre trabalho, sexualidade, linguagem e mercado, mesmo quando estão subsumidos às estratégias ou investimentos da racionalidade neoliberal. Ressaltese que isso se decorre porque trabalho, sexualidade, linguagem e mercado apenas entram em equilíbrio unívoco provisório e reajustável às custas de forçosas codificações hierárquicas de seus campos específicos de vida, o que se segue por meio da pujança de 
uma racionalidade dominante neoliberal que, oprimindo sem se fazer sentir, opera com clamor de unidade contra a multiplicidade do vivido descentrado dos campos anunciados (trabalho, desejo, linguagem etc.).

Além do mais, e essa já é uma segunda ponderação, os investimentos dessa racionalidade só se atualizam de modo eficaz porque se travestem de processos vivos tal como fisionomias simuladas de vida, camuflando-se e expandindo-se na forma de modelos naturalizados de ação social tidos como autênticos, justamente lá onde apenas são artifícios. Trata-se, neste caso, de conferir uma dinâmica silenciosa de produção de sujeitos por disfarce, ao compasso funcional das distintas esferas institucionais que circunscrevem direta ou indiretamente trabalho, sexualidade, linguagem e mercado. Essa dinâmica, portanto, só é eficaz justamente porque procede com a precisão de saber tecnicamente que, no campo institucional preciso no qual atua, ou seja, lá onde o sujeito é passível de ser produzido por interpelação (a da sexualidade, por exemplo), uma estratégia de captura e produção de vida determinada só tem vazão por proceder como espécie de mimese especifica de um aspecto da vida para a qual se volta à ocasião, demarcando assim evidentes restrições por simulação, restrições as quais passam a bloquear a infinidade de possibilidades de expressão da própria vida individual. É decerto esse aspecto mimético, ou melhor, de simulação, que tem então a força de codificar e delimitar as condutas (mesmo aquelas antes ainda não expressas) sob a égide da racionalidade dominante neoliberal. Podemos assim ressaltar que a racionalidade dominante neoliberal simula, imita producentemente vidas que, entretanto, de modo substantivo não reduzem seu sentido originário (como aquele que se desdobra em sexualidade e trabalho, por exemplo) ao controle biopolítico do neoliberalismo como único lugar possível de afirmação. É precisamente neste sentido que, como diz Vladmir Safatle em seu recente Circuito dos afetos (2015), jamais "chegaremos à atividade vital [naquilo que dela é realmente significativo] intensificando os processos internos ao capitalismo, mesmo que 
| 198 |

A captura e produção da sexualidade...

em sua dinâmica o capitalismo procure, à sua maneira, mimetizar a vida"15 (SAFATLE, 2015, p. 453-4).

Mas, por outrolado, éjustamente ao passo que uma simulação producente de condutas viventes repete-se biopoliticamente, na forma de artifícios orgânicos de uma racionalidade dominante neoliberal, que se faz seguir modos de produção de vida que já não estão inteiramente vinculados à potência imanente (a ser ética e politicamente visada) factualmente transformadora, seja imanente às formas de desejar, de se relacionar ou de laborar.

\begin{abstract}
O neoliberalismo não é apenas um modo de regulação dos sistemas de trocas econômicas baseado na concorrência e do dito livre comércio. Ele é um regime de gestão social e produção de formas de vida que traz uma corporeidade específica, uma corporeidade neoliberal. Margareth Thatcher mostrou ao menos a virtude da honestidade de afirmar que "a economia é o método. O objeto é modificar o coração e a alma". Se Thatcher tivesse lido Foucault, ela complementaria afirmando que o coração e a alma são peças na dominação que o poder exerce sobre o corpo. [...] há uma instauração sensível da vida psíquica cujos mecanismos precisam ser compreendidos. É necessário ter isso em mente quando se perguntar o que seria então esse novo homem neoliberal, qual sua economia libidinal (SAFATLE, 2015, p. 95-6).
\end{abstract}

Construamos um exemplo a partir do que está supracitado. Ressaltemos aqui o erro em que incorrem alguns grupos de homossexuais ao peticionar em lutas políticas, conquanto nos marcos de um paradigma jurídico de racionalidade neoliberal, a demanda de aceitação institucionalizada de sua opção sexual como forma de vida, o que, numa ressonância, acaba por tender justamente à biopolítica da simulação producente de suas vidas, porquanto passem a se mover e direcionar suas expectativas aos

\footnotetext{
${ }^{15}$ Informações entre colchetes elaboras pelos autores do presente escrito.
} 
limites estritos do paradigma da sexualidade juridicamente situada de modo neoliberal. No limite, poderão incorrer num duplo erro, o primeiro deles sendo o de descambarem nos limites de uma petição a partir da qual solicitam que as instituições jurídicas (em autoconservação nos limites da racionalidade neoliberal, portanto) legitimem contratualmente (à lógica de subjetividades de pares que se relacionam ao modo capitalista da elaboração de contratos para aquisição propriedades particulares, e apesar da homofobia institucional burguesa imanente também às organizações jurídicas) a homoafetividade como discurso jurídico de gênero e enquanto direito social. Neste caso preciso, alguns grupos homoafetivos, em realidade, estão a peticionar uma guarida jurídica que poderá produzir um novo campo de concentração cultural igualmente preconceituoso, porquanto negociar com o inimigo a partir de suas cartas é entrar num jogo em que já sabemos de partida, mesmo antes da partida se iniciar, quem irá ganhar. Trata-se, portanto, de se voltar contra si mesmo. Como agravante, ressalte-se a isso o fato histórico de que

\begin{abstract}
os dispositivos constitucionais se assemelham cada vez mais ao modelo europeu de uma convenção econômica cuja elaboração não emana de qualquer poder constituinte popular, tampouco requer a existência de um Estado, basta moeda e Banco Central, pois se trata apenas de assegurar a vida bruta do capital (ARANTES, 2014, p. 318).
\end{abstract}

Já o segundo erro de alguns desses grupos determinados tem uma gravidade ainda maior. Ele pode ser atestado pelo fato de que a petição da legitimação jurídica de modelos contratuais, segundo a qual são reinauguradas institucionalmente as relações de gênero, poderá, com a própria contribuição de casais homoafetivos, transmutar-se no parâmetro de uma nova tecnologia de dominação, destinada objetivamente tanto a cristalizar presentes formas vivas de relação quanto impedir que incipientes modos de relação social se afirmem como novidade. Neste caso, a demanda por direito social homoafetivo, quando instaurada tanto 
não irá servir como meio de liberdade quanto será utilizada como objeto de novas hierarquizações e opressões culturais de gênero (que é múltiplo em seus modos de expressão, não se restringindo a modelos preestabelecidos), à esteira de uma simulação biopolítica da sexualidade "patologizadora" de grupos sociais no bojo da "fixidez de uma configuração estática da estrutura normativa" (SAFATLE, 2015, p. 434).

Aqui, portanto, jaz um evidente exemplo de como a sexualidade poderá ser simulada enquanto forma de vida administrada aparentemente transformadora. Nesse sentido, é o próprio modo de autocompreensão de si mesmo como posição topológica de um determinado grupo social que é refletido do ponto de vista de uma sexualidade já mediada por uma espécie de politização jurídico-biopolítica da cultura de gênero, por meio de que os próprios representantes da cultura de gênero são estrategicamente persuadidos a demandar direitos sócio-culturais às instituições neoliberais, cuja natureza é a de claramente contra eles se voltar ${ }^{16}$.

A pretensão de ser institucionalmente aceito torna-se a justa operação de, selando-se um pacto entre cultura de minorias, direito, Estado e capital, produzir-se um sujeito homoafetivo juridicamente mediado, possivelmente tornando unidimensional o campo vital da diversidade de gênero ${ }^{17}$. Levando em consideração

\footnotetext{
${ }^{16}$ Excelentes trabalhos críticos sobre a relação entre o Estado e o direito como espaço legal tanto de exceção quanto de demanda social foram desenvolvidos por Giorgio Agamben a partir de Foucault. Conferir, por exemplo, Agamben (2005 e 2004). Sobre o livro Profanações conferir excelente entrevista concedida pelo filósofo italiano ao jornal Folha de São Paulo no dia 18 de outubro de 2005, disponível em: <http://www1.folha.uol.com.br/fsp/mais/fs1809200505. htm>. Numa esteira mais marxista conferir o trabalho recém traduzido para o português de Bernard Edelman (2016). Do ponto de vista de uma etnografia brasileira atualizada, conferir a relação entre direito, cidadania, democracia, diferenças sociais e disputas por terra em Holston (2013).

${ }^{17}$ Para maiores pesquisas sobre este ponto, conferir também, por exemplo, obras de Judith Butler, nas quais, com um pé em Foucault, como sempre, parece seguir na mesma linha de argumentação supracitada, ao se voltar contra certos tipos
} 
isso, podemos enfim concluir que a potência de indeterminação do desejo e da sexualidade de uma vida não capturada (porque ainda não predeterminada em seu modo viver) cai inteiramente por terra. Ora, é justamente isso que não podemos aceitar.

Nossas sociedades contemporâneas são atravessadas por questões justas ligadas à ampliação do direito ao casamento para casais homossexuais, criando, com isso, a exigência de ordenamentos jurídicos igualitários no que diz respeito ao casamento. No

de discursos representativos do Eu fixado de gênero, os quais têm a propensão de capitular perante à pretensão de se deixarem subsumir binariamente às lógicas de constituição identitária nos marcos da racionalidade do capitalismo contemporâneo. Todavia, como alerta Safatle (2015) em posfácio da obra Butler (2015): "devemos lembrar como Butler aborda os problemas ligados à experiência do sexual em uma era histórica marcada por dois fenômenos centrais, o que define muito da peculiaridade de seu pensamento. Primeiro, a ascensão, a partir dos anos setenta, das lutas políticas de reconhecimento do que fora visto até então como socialmente minoritário (gays, mulheres, negros, travestis). Minoritário não no sentido de ser uma minoria numérica, mas de ser compreendido como marcado por uma minoridade social. No entanto, longe de aceitar que tais lutas representariam um deslocamento da política em direção ao campo da afirmação de "diferenças culturais" cada vez mais particularistas e críticas a qualquer forma de universalidade, Butler vê em tais lutas a possibilidade do advento de uma forma social caracterizada pelo reconhecimento dos limites de toda e qualquer identidade [...] Desta forma, Butler pode sintetizar a crítica do capitalismo enquanto forma social baseada na organização da vida a partir de um princípio de identidade que anima a figura do indivíduo. Uma crítica que não se contentará nem com a estratégia de multiplicação multicultural das identidades, nem com algumas formas de experiências comunais substancialmente enraizadas perdidas pelo processo de modernização capitalista" (SAFATLE, 2015, p. 176-8). Para concluir vejamos o que a própria Judith Butler nos diz conclusivamente: "O si-mesmo em questão é claramente 'formado' dentro de um conjunto de convenções sociais que suscitam a pergunta sobre se é possível ter uma boa vida dentro de uma má, e se deveríamos, ao nos reinventarmos com o outro e pelo outro, participar da recriação das condições sociais". Que podem envolver mutilações internas da consciência (BUTLER, 2015, p. 170-71). 
|202 |

A captura e produção da sexualidade...

entanto, uma perspectiva realmente mais consequente deveria radicalizar essa demanda afirmando que cabe ao Estado simplesmente deixar de legislar sobre a forma do matrimônio, limitando-se a legislar única e exclusivamente sobre as relações econômicas entre casais ou outras formas de "agrupamentos afetivos". Seria uma maneira de radicalizar o princípio de abertura do casamento a modelos não ligados à estrutura disciplinar da família heterossexual burguesa, com seu modo de gestão biopolítico da vida. Em vez de ampliar a lei para casos em que ela não contemplava (como os homossexuais), deveríamos simplesmente eliminar a lei criando uma zona de indiferença [cultural] desinstitucionalizada. [...] O Estado, com seu ordenamento jurídico, deve legislar sobre questões de ordem econômica, não sobre questões de ordem afetiva. [...] Nada impede que o Estado legisle sobre questões estritamente econômicas do casamento e das uniões estáveis (se entre homem e uma mulher, duas mulheres e um homem etc.) [...] no que diz respeito a formas afetivas, não cabe ao ordenamento jurídico predicar previamente os possíveis, mas acolher as efetivações múltiplas dos possíveis. Do ponto de vista do direito, tal multiplicidade deve ser indiscernível [...] Por mais que isso pareça ser contraintuitivo, a verdadeira política está sempre além da afirmação das identidades, sejam individuais ou coletivas. Ela inscreve, em estruturas sociais amplas, modalidades antipredicativas de reconhecimento que encontram sua manifestação em dimensões sociais da linguagem e do desejo [...] (SAFATLE, 2015, p. 363).

E um dos passos para essa resistência talvez seja fundamentalmente próprio da espessura tangencial de um desejo e de uma sexualidade implicados numa caminhada de abertura aos caminhos e possibilidades antes ainda imprevistos pelo campo da cultura e da subjetividade liberal possessiva nela envolvida, com imprevisibilidades irrepetíveis e não cristalizáveis. Assunto que será melhor desenvolvido em trabalhos futuros. 


\section{Referências}

AGAMBEN, G. Profanações. São Paulo: Boitempo Editorial, 2005.

Estado de exceção. São Paulo: Boitempo Editorial, 2004.

ARANTES, P. E. O novo tempo do mundo: e outros estudos sobre a era da emergência. São Paulo: Boitempo, 2014.

BATAILLE, G. [1957] O erotismo. Trad. Fernando Scheibe. Belo Horizonte: Autêntica, 2014.

BRAUDEL, F. [1979]. Civilização material economia e capitalismo - séculos XV-XVIII - Os jogos das trocas. Trad. Telma Costa. São Paulo: Martins Fontes, 1996.

BUTLER, J. [2005]. Relatar a si mesmo: crítica da violência ética. Trad. Rogério Bettoni. Belo horizonte: Autêntica, 2015.

DARDOT, P.; LAVAL, C. [2010]. A nova razão do mundo: ensaios sobre a sociedade neoliberal. Trad. Mariana Echalar. São Paulo: Boitempo, 2016.

DEJOURS, C. [1998]. A banalização da injustiça social. Trad. Luis Alberto Monjardim. 7ª ed. Rio de Janeiro: FGV, 2015.

DUNKER, C. I. L. Mal-estar, sofrimento e sintoma: uma psicopatologia do Brasil entre muros. São Paulo: Boitempo, 2015.

O esgotamento da democracia liberal a $61 \%$. Blog da Boitempo, São Paulo, 11 de abril de 2016. Disponível em: $<$ https://blogdaboitempo.com.br/2016/04/11/o-esgotamento-dademocracia-liberal-a-61/>. Acesso: em 11 abr. 2016.

EDELMAN, B. A legalização da classe operária. São Paulo: Boitempo Editorial, 2016.

FOUCAULT, M. [1997] Em defesa da sociedade: Curso no Collège de France. Tradução: Maria Ermantina Galvão. São Paulo: Martins Fontes, 2005.

[1976] História da sexualidade 1: A vontade de saber. Trad. Maria Thereza da Costa Albuquerque e J. A. Guilhon de Albuquerque. Rio de Janeiro: Graal, 1993. 
[1980] L'impossible prison, recherches sur le système pénitentiaire au XIX siècle. Paris: Éd. du Seuil, 1980. [1979] Microfísica do poder. São Paulo: Graal, 2008. [2004] Nascimento da biopolítica: Curso no Collège de France. Trad. Eduardo Brandão. São Paulo: Martins Fontes: 2008. [1975] Vigiar e punir: nascimento da prisão. Trad. Raquel Ramalhete. Petrópolis: Vozes, 2008.

GADELHA, S. Biopolítica, governamentalidade e educação: introdução e conexões, a partir de Michel Foucault. Belo Horizonte: Autêntica, 2009.

GUATTARI, F. [1989] As três ecologias. Trad. Maria Cristina F. Bittencourt. Campinas: Papirus, 1990.

HOLSTON, J. Cidadania Insurgente: disjunções da democracia e da modernidade no Brasil. São Paulo: Companhia das Letras, 2013.

KEHL, M. R. O tempo e o cão. São Paulo: Boitempo Editorial, 2009.

MACHADO, R. Introdução - Por uma genealogia do poder In: FOUCAULT, Michel. Microfísica do poder. São Paulo: Graal, 2008.

MORAES, E. R. Traços de Eros. In: BATAILLE, G. O erotismo. Belo Horizonte: Autêntica, 2014.

PELBART, P. P. [2003] A vida capital: Ensaios de Biopolítica. São Paulo: Iluminuras, 2009.

SAFATLE, V. Cinismo e falência da crítica. São Paulo: Boitempo Editorial, 2008.

O circuito dos afetos: corpos políticos, desamparo e o fim do indivíduo. São Paulo: Cosac Naify, 2015.

VIANA, S. Rituais do sofrimento. São Paulo: Boitempo Editorial, 2013.

ŽIŽEK, S. [2008] Violência: seis reflexões laterais. Trad. Miguel Serras Pereira. São Paulo: Boitempo Editorial, 2014. 